\title{
A RECEPTIVIDADE AOS PROTESTANTES EM FEIRA DE SANTANA (1937-1955)
}

\author{
Leonardo Nascimento Araújo ${ }^{1}$ e Elizete da Silva ${ }^{2}$ \\ 1. Bolsista PIBIC/CNPq, Graduando em Licenciatura em História, Universidade Estadual de Feira de Santana, \\ e-mail: leo.nascimento.12@live.com \\ 2. Orientador, Departamento de Ciências Humanas e Filosofia, Universidade Estadual de Feira de Santana, e-mail: \\ cliosilva@yahoo.com.br
}

PALAVRAS-CHAVE: Protestantismo; disputas; Feira de Santana,

\section{INTRODUÇÃO}

Esta pesquisa investiga a reação dos grupos religiosos à presença protestante em Feira de Santana provocando disputas no campo religioso feirense abrangendo o período de 1937 a 1955, quando foi implantada em Feira de Santana a primeira igreja protestante, sob a direção do missionário Roderick Gillanders e sua esposa, a missionária Isobel Gillanders. Esta chamava-se Igreja Evangélica Unida e professava o Congregacionalismo como confissão de fé protestante.

Para compreender o Congregacionalismo em Feira de Santana, é pertinente revisitar a sua chegada em solo brasileiro. No capítulo Os sentidos da árvore e da democracia: uma história dos congregacionais no Brasil, incluído na obra Fiel é a Palavra: leituras históricas dos evangélicos no Brasil, Lyndon de Araújo dos Santos trata da influência protestante do médico Robert Reid Kalley e sua esposa Sarah Kalley estabelecendo-se na cidade de Niterói (RJ) em 1855. Segundo Santos, Kalley era um representante tanto das tradições protestantes inglesas, como do universo congregacionalista (SANTOS, 2011, p. 136) e, sobre o processo de institucionalização e formação da igreja com suas características denominacionais, Santos afirma:

A primeira igreja foi fundada em 1858, com o batismo de brasileiros e portugueses que formaram o núcleo da Igreja Evangélica Fluminense. O nome representava a forma de governo (igreja autônoma e independente), a identidade religiosa (evangélica) e o lugar de seu pertencimento (Fluminense). O perfil social de seus membros foi sendo estabelecido entre as pessoas simples, negros escravos e forros, brancos, pobres, trabalhadores e mulheres (...) Dessa forma, as igrejas congregacionais tiveram a liberdade de associação em comunidades livres, sem impedimentos, embora tenham sofrido perseguições por parte da Igreja Católica (SANTOS, 2011, p. 138).

Pastores e missionários vindos da Europa e posteriormente dos EUA chegaram no País com a intenção de fazer proselitismo e converter os brasileiros às doutrinas protestantes. Seguindo a linha do protestantismo de missão, a Igreja Evangélica Fluminense foi a primeira a ser implantada em solo brasileiro com esse fim (LÉONARD, 2002). Os anglicanos, por sua vez, chegaram em 1819, porém, diferente dos congregacionais, os episcopais realizavam os seus cultos em inglês, sem intenção de proselitismo direto (SILVA, 2017).

A cidade de Feira de Santana, no interior da Bahia tornou-se um dos municípios visitado por protestantes realizando a colportagem, isto é, venda de Bíblias e materiais de literatura, inicialmente em 1889, com as atividades do missionário presbiteriano Rev. George Chamberlain, que distribuiu Bíblias e folhetos evangélicos e realizou cultos públicos (TRABUCO, 2014, p. 94).

Neste período o município de Feira de Santana, passava por mudanças no âmbito populacional, econômico, político e social. Localizada no interior da Bahia, o município incorporou, paulatinamente, características de zona urbana com a chegada de tecnologias, novos costumes e o deslocamento de famílias interioranas bem como de outros Estados do Nordeste para trabalhar e viver na cidade (OLIVEIRA, 2012). 
O Protestantismo configura-se como parte dessas mudanças ocorrentes em Feira de Santana. Como afirma Aline Aguiar: "para se entender uma cidade, pode-se observar cada aspecto do seu cotidiano, não tem nada melhor do que analisar as formas de diversões, bem como as sociabilidades tecidas em suas malhas" (SANTOS, 2016, p. 152). Gradativamente, o Protestantismo encontrou-se entre as formas de sociabilidades presentes no município de Feira deSantana.

Apesar dos esforços do Rev. Chamberlain, não houve a formação de uma igreja a partir da sua iniciativa, pois o mesmo precisou ser transferido para Cachoeira. Zózimo Trabuco afirma a respeito da chegada do casal Gillanders:

Em 1935 chegaram a Feira de Santana missionários da Sociedade Bíblica Britânica e Estrangeira, o casal neozelandês Isobel C. Gillanders e Roderick Gillanders. O casal organizou, em 1937, a Igreja Evangélica Unida, primeira igreja local do protestantismo em Feira de Santana (...) Nas memórias da Igreja Evangélica Unida, a missionária Isobel Gillanders descreveu a divisão das atividades "entre fundar uma igreja e visitar cidades vizinhas e o mercado local para vender Bíblias” (TRABUCO, 2014, p. 95).

Na obra memorialística A história inacabada, a missionária Isobel Gillanders descreveu alguns desses conflitos resultantes da não aceitação das doutrinas protestantes pelos católicos feirenses, devido à hegemonia da Igreja Católica que não admitia a presença de outras doutrinas concorrentes, a exemplo da mensagem protestante divulgada pelo casal Gillanders em Feira de Santana na implantação da Igreja Evangélica Unida. (GILLANDERS,1990). No decorrer dos anos, os conflitos foram aplacados à medida em que as denominações protestantes se expandiam por Feira de Santana, ampliando o campo religioso na cidade.

Na década de 1950, a Igreja Evangélica Unida desligou-se da União das Igrejas Evangélicas Congregacionais do Brasil. Alguns fatores poderiam ter propiciado esse desligamento, como plena autonomia enquanto comunidade local, ou seja, sem afiliações denominacionais ou de ordem político-eclesiástica, sendo que, os motivos desse desligamento ainda são alvos de investigação histórica. A Igreja Evangélica Unida, entretanto, manteve fortes vínculos doutrinários com a UESA (União Evangélica Sul-Americana) desde a década de 1940. Na mesma década, a igreja conclui a construção do seu prédio para atividades cúlticas (OLIVEIRA, 2007).

\section{MATERIAL E MÉTODOS OU METODOLOGIA (ou equivalente)}

O proselitismo feito pelos missionários protestantes em Feira de Santana foi motivado pela ideia de vocação e chamado estabelecidos por Deus. Max Weber reafirma o conceito de vocação em Martinho Lutero e os outros grupos protestantes como "Aquilo que o ser humano tem de aceitar como desígnio divino, ao qual tem de "se dobrar" (WEBER, 2004, p. 77). A pesquisa usa como base teórica o conceito de campo religioso do sociólogo Pierre Bourdieu. Segundo ele, o campo religioso é "relativamente autônomo e o desenvolvimento de uma necessidade de 'moralização' e de 'sistematização' das crenças e práticas religiosas" (BORDIEU, 1974, p. 34). Em Bourdieu, o conceito de campo religioso é usado para entender as relações e disputas entre os diversos grupos religiosos. Para o desenvolvimento da pesquisa histórica, levantamos as seguintes fontes:

\section{Fontes escritas:}

a) Jornal Folha do Norte de 1937 a 1964.

b) Atas das Assembleias da Igreja Evangélica Unida e da Igreja Evangélica Fundamentalista dos anos de 1949 a 1964. 
e) Livro E a história continua... com relatos de 1955 a 2007.

f) Os 28 Artigos de fé da Igreja Evangélica Congregacional do Brasil de 1858.

2. Fontes orais:

1) Rev. Antônio Ribeiro Fernandes de Oliveira.

2) Lélia Vitor Fernandes de Oliveira.

3) Lídia Nascimento.

4) Presbítero Florentino.

5) Membros remanescentes da Primeira Igreja Evangélica Congregacional de Feira de Santana e da Igreja Evangélica Fundamentalista.

\section{RESULTADOS E/OU DISCUSSÃO (ou Análise e discussão dos resultados)}

a) A divisão da Igreja Evangélica Unida e desligamento da mesma da União das Igrejas Evangélicas Congregacionais do Brasil tornando-se uma igreja congregacional independente.

b) Uma parte dos membros que se retirou da Igreja Evangélica Unida possivelmente formou a Primeira Igreja Evangélica Congregacional e a Primeira Igreja Presbiteriana de Feira de Santana.

c) A transformação da Igreja Evangélica Unida para Igreja Evangélica Fundamentalista em 1964, em decorrência do conservadorismo politico e religioso após o golpe militar e a instalação da Ditadura, quando os líderes religiosos protestantes no Brasil se declaravam mais tradicionais e contra as ideias de orientação socialista (ALMEIDA, 2010).

\section{CONSIDERAÇÕES FINAIS (ou Conclusão)}

Com o crescimento da Igreja Unida em Feira de Santana e o conservadorismo politico e eclesiástico pós-golpe militar no Brasil na década de 1964, ocorreu a mudança doutrinária transformando-se em Igreja Evangélica Fundamentalista, ou seja, uma linha teológica que reafirmava os embates contra o ecumenismo e as propostas da Teologia da Libertação que foram aceitas pelos protestantes progressistas no Brasil e em Feira de Santana. $\mathrm{O}$ estadunidense presbiteriano Carl McIntire foi o principal mentor e proponente do Fundamentalismo no Brasil influenciando consideravelmente a Igreja Evangélica Fundamentalista em Feira de Santana (SILVA, 2010). A extensão do recorte temporal para 1964 nesta pesquisa procura investigar os fatores de mudança e a suas possíveis relações com o contexto político-social da Ditadura Militar no Brasil aproximando-se de Feira de Santana.

\section{REFERÊNCIAS}

AGUIAR, Aline in LEITE, Rinaldo César Nascimento Leite, Aline Aguiar Cerqueira dos Santos, Miranice Moreira da Silva (orgs.). Cidades interioranas da Bahia: Modernidade, civilidade e sociabilidades. Feira de Santana, UEFS Editora, 2016.

ALMEIDA, Luciane Silva de. "O Comunismo é o ópio do povo": Representações dos Batistas sobre o comunismo, o ecumenismo e o Governo Militar na Bahia (1996- 1975). Dissertação de Mestrado em História Social pela UEFS, Feira de Santana, 2010.

ALMEIDA Vasni de; SILVA Elizete de; SANTOS Lyndon Araújo de (org.). "Fiel é a Palavra": leituras históricas dos evangélicos protestantes no Brasil. Feira de Santana: UEFS Editora, 2011. 
BOURDIEU, Pierre. A Economia das Trocas Simbólicas. São Paulo: Perspectiva, 1987.

LEONARD, Émile G. O Protestantismo brasileiro: estudo de eclesiologia e história social. São Paulo, ASTE, 2002.

OLIVEIRA, Clóvis Frederico Ramaiana Moraes. "Canções da cidade amanhecente": urbanização, memórias urbanas e silenciamentos em Feira de Santana, 1920-1960. Tese de doutorado pela Universidade de Brasília, Programa de Pós-Graduação em História.

PANASIEWICZ Roberlei. Fundamentalismo religioso: história e presença do cristianismo. Belo Horizonte, PUC Minas. (S.l), (S.d.).

SANTOS, Lyndon Araújo dos. Os sentidos da árvore e da democracia: uma história dos congregacionais no Brasil. In SILVA, Elizete da, Lyndon de Araújo dos Santos, Vasni de Almeida (orgs.). "Fiel é a Palavra": Leituras históricas dos evangélicos protestantes no Brasil. Feira de Santana, UEFS Editora, 2011.

SILVA, Elizete da. História das Religiões: Perspectivas e abordagens. In QUADROS, Eduardo Gusmão de, Marta da Conceição Silva (orgs.). Sociabilidades religiosas: mitos, ritos e identidades. São Paulo, Paulinas, 2011.

Sagga, 2017.

Cidadãos de outra pátria: Anglicanos e batistas na Bahia. Salvador,

. Protestantismo ecumênico e realidade brasileira: Evangélicos progressistas em Feira de Santana. Feira de Santana, UEFS Editora, 2010.

. O campo religioso feirense: notícias e reflexões preliminares. Revista

Sitientibus. Feira de Santana, UEFS, n. 41, jul. /dez. 2009, p. 27-46.

TRABUCO, Zózimo Antônio Passos. A seara e os ceifeiros: Educação teológica, narrativas de conversão e identidade batista (1960-1990). Feira de Santana, UEFS Editora, 2014

WEBER, Max. A Ética Protestante e o espírito do Capitalismo. São Paulo, Companhia das Letras, 2004. 